\title{
GRAMÁTICA CATEGORIAL E PROCESSAMENTO LINGÜÍSTICO
}

Luiz Arthur Pagani*

\section{Introdução}

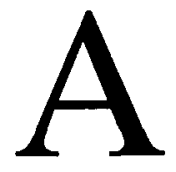

lém de sua elegância formal, amplamente reconhecida, outra vantagem da gramática categorial é sua compatibilidade com princípios psicolingüísticos de desempenho. Mais especificamente, essa gramática é perfeitamente adequada à chamada interpretação incremental, segundo a qual 'a nossa compreensão das sentenças é 'incremental', no sentido de que cada palavra sucessiva parece contribuir para a acumulação gradual do significado mais ou menos logo após ela ter sido encontrada" (Steedman, 1989, p. 463).

Assim, o objetivo deste artigo é o de apresentar, na próxima seção, o conceito de interpretação incremental e, logo a seguir, discutir a proposta de

* Professor da Universidade Estadual de Londrina e doutorando do programa de PósGraduação no Instituto de Estudos da Linguagem da Universidade Estadual de Campinas. 
Steedman para resolver a contradição direcional' entre as ramificações à direita - estabelecida pelas análises gramaticais correntes - e à esquerda - definida pela incrementalidade da interpretação; segundo Steedman, a adoção de uma gramática categorial, completamente compatível com a ramificação à esquerda, descaracteriza a contradição. Finalmente, na última seção, apresentaremos as conclusões sobre a solução de Steedman e as restrições sobre a forma como ele acredita que sua proposta represente os princípios psicolingüísticos de "ligação mínima" (minimal attachment) e de "associação à direita" (right association, late closure ou final arguments).

\section{Interpretação incremental e labirintos sentenciais}

A noção de incrementalidade serviu inicialmente para salvar o conceito de modularidade das contestações dos interacionistas; ainda que um modelo modular seqüencial clássico não possa dar conta de fenômenos nos quais algum paralelismo pareça estar envolvido, o modelo incremental apresenta uma equivalência fraca com os modelos interacionistas, devido à sua capacidade de explorar em profundidade qualquer informação tão logo ela esteja disponível, sem a necessidade de esperar pela análise integral de toda a sentença ou mesmo de apenas um sintagma qualquer.

Para Crocker (1996, p. 2), "a operação do processador de sentenças e de seus módulos constituintes é determinada por um princípio globalizante de compreensão incremental. Este princípio garante o máximo uso das informações linguiísticas, assim que cada uma das palavras proferidas são encontradas." Dessa forma, supondo que, durante sua execução, o processamento lingüístico passe por um módulo sintático e por outro semântico, ${ }^{2}$ não há ne-

1 Esta contradição direcional da análise ficou conhecida como "paradoxo pedestre", devido a um tex to de Stabler (1992), onde ele afirma que a gramática gerativa não impōe necessariamente a ramificação à direita. Como o aspecto da argumentação de Steedman é o da compatibilidade com a interpretação incremental, e a restrição que iremos apontar está no relacionamento que ele estabelece entre o desempenho e o processamento sintático, remetemos o leitor interessado ao próprio texto de Stabler (onde há inclusive uma demonstração formal em Prolog).

2 Não é demais observar que, como é possível perceber, não estamos afirmando que o processamento lingüístico se restringe apenas aos módulos sintático e semântico; ele ainda envolve, possivelmente, os módulos fonético, fonológico, morfológico e pragmático. A quantidade exata de módulos, no entanto, não é importante; o que basta para o exemplo é a relação entre dois módulos. Como o modelo incremental pressupōe um processamento linear, supõe-se ainda que esse tipo de relação se difunde seqüencialmente entre os módulos. 
cessidade de supor que o primeiro módulo termine completamente a análise sintática de uma sentença como "Pedro corre", para que só depois o segundo módulo faça a interpretação semântica. Num processamento incremental, assim que o módulo sintático reconhece que "Pedro" é da categoria dos nomes próprios, essa informação já é transmitida ao módulo semântico, que já pode começar a interpretá-lo; enquanto isso, o módulo sintático já está novamente livre para processar "corre". Assim que este é reconhecido como um verbo, ele já pode ser disponibilizado para ser interpretado; e enquanto o módulo semântico interpreta essa segunda palavra, o módulo sintático já pode estar procurando a relação sintática entre elas. Depois disso, finalmente, o processador pode integrar as interpretações. ${ }^{3}$

Ainda segundo o mesmo autor (Crocker, 1996, p. 4),

a noção de incrementalidade segue, em parte, da idéia intuitiva de que as pessoas parecem entender as sentenças assim que elas são ouvidas, aparentemente palavra por palavra, ao invés de esperar pelas fronteiras de sentença, de oração, ou mesmo de sintagma. Ou seja, nós não apenas obtemos os referentes semânticos de cada palavra, como ainda atribuímos rapidamente uma estrutura gramatical à entrada, tão logo as palavras são encontradas, de modo que uma interpretação semântica composicional possa ocorrer imediata e incrementalmente.

Além dessa evidência intuitiva sobre a incrementalidade, existem também evidências empíricas, obtidas através de experimentação psicolingüística, de que a interpretação seja realmente incremental. Um fenômeno de ambigüidade local, conhecido como garden-path, ${ }^{4}$ cuja primeira observação é atribuída a Bever (1970) e que foi objeto de testes psicolingüisticos (Frazier, 1979; Frazier; Rayner, 1982), demonstrou que os individuos tendem a escolher apenas uma das análises disponíveis, e que a escolha não depende de informações semânticas, mas sim de critérios de economia estrutural - os citados princí-

3 Um modelo desse tipo provavelmente ainda exigiria algum controle na transmissão das informações de um módulo para o outro, de forma que uma informação não fosse recebida enquanto 0 módulo ainda estivesse ocupado com um processamento anterior, o que poderia acarretar em perda de informação; um simples buffer poderia resolver esse problema, mas como esta questão foge aos interesses deste texto, não a discutiremos aqui.

4 No subtítulo desta seção, traduzimos o termo garden-path sentence por labirinto sentencial; outra solução, que soa mais empolada, seria sentença labiríntica. 
pios de "ligação mínima" e de "associação à direita". A comprovação dessas estratégias de soluções locais leva diretamente à conclusão de que "a análise sintática atua sobre fragmentos de sentenças" (Chater; Pickering; Milward, 1995, p. 3), e não apenas sobre a sentença como um todo; e o mesmo pode ser dito da interpretação semântica.

Um dos exemplos mais famosos de garden-path é a sentença The horse raced past the barn fell. Nessa sentença, a tendência da maioria dos falantes do inglês - demonstrada experimentalmente ${ }^{5}$ - ao encontrar a palavra raced é a de analisá-la como o verbo principal da sentença; no entanto, ao se deparar com a palavra fell, que não pode mais ser integrada à sentença da forma como ela vinha sendo analisada, o falante é obrigado a refazer a análise da sentença. A revisão da análise levaria o falante a invocar a segunda possibilidade categorial de raced, como particípio passado, reanalisando raced past the barn como uma oração adjetiva reduzida; dessa forma, fell pode ser finalmente integrado como o verbo principal da sentença. A sustentação empírica para esta interpretação do fenômeno é o aumento do tempo de reação medido nesta última palavra, tanto através de tarefas posteriores (como decisão lexical e juizo de gramaticalidade) quanto através de tarefas intervenientes (como movimento ocular e leitura autocadenciada - self-paced reading).

No português, esse tipo de sentença parece ser mais raro, devido princiJalmente à estrutura morfológica mais complexa do que a do inglês, que pernite uma ambigüidade categorial muito maior. Por isso, as únicas sentenças que conseguimos encontrar até agora que apresentam esse tipo de fenômeno उão $O$ navio angolano entrava no porto o navio brasileiro ${ }^{6}$ e Estou com vontate de ver o filme da Sharon Stone novamente. ${ }^{7}$

$\mathrm{Na}$ primeira sentença, entrava é inicialmente analisado como pretérito imperfeito do verbo entrar; mas, por esta análise, o sintagma nominal o navio brasileiro não pode ser integrado ao resto da sentença. A única solução é

5 Como a quantidade de referências seria enorme, ao invés de escolher algumas, preferimos remeter o leitor ao primeiro caṕtulo de Frazier; Clifton (1996), onde elas são exaustivamente citadas e comentadas.

6 Este exemplo eu devo a João Luís Garcia Rosa; no entanto, como bem observou Edson Françozo, este ainda não é exatamente o mesmo fenômeno porque também envolve seleção de dois itens distintos, o que não acontece no garden-path em inglês.

7 Na verdade, este exemplo foi adaptado de uma piada mais maldosa que um antigo colega fazia.

8 Em todas as vezes que vi este exemplo ser apresentado, as pessoas sempre demonstravam alguma dificuldade para reconhecer esta segunda solução. Além da questão da escolha lexical (comentada na nota 6), outro fator que pode estar complicando o processamento desta sentença é a diferença na freqüiencia de uso dos dois itens lexicais envolvidos. 
reanalisar o verbo como presente de entravar que, como verbo transitivo, permite a integração do sintagma nominal. ${ }^{8}$

A segunda sentença será preferencialmente interpretada pelos falantes de português como sendo compatível com a situação em que o tal filme já foi visto e a pessoa deseja revê-lo. Contudo, ela ainda é compatível com uma segunda situação, na qual o filme ainda não teria sido visto, mas também aquela não seria a primeira vez que a pessoa desejaria vê-lo. ${ }^{9}$

\section{Paradoxo pedestre e hipótese forte da competência}

Esse tipo de mudança de abordagem - do sistema para o processo trouxe uma nova perspectiva para a análise linguística. Ao contrário do que ocorria na tradição da lógica - que definia as condições de boa-formação de uma fórmula - e da gramática gerativa - que estabelece quais sentenças são gramaticais numa língua - a questāo passa a ser a de como cada unidade lingüística é seqüencialmente justaposta a outra, de forma a constituir uma unidade maior. Em relação a isso, parece haver uma contradição entre as tradições de análise lingüística mencionadas e as evidências que apontam para a incrementalidade interpretativa.

Segundo Steedman (1989, p. 463),

espera-se que as regras de uma gramática [de uma língua] natural devam corresponder diretamente aos passos que um processador executa quando compõe uma análise. Aceita essa hipótese, os únicos componentes adicionais, além da própria gramática, são um mecanismo para a construção de estruturas interpretáveis, segundo as regras da gramática, e um mecanismo para a solução das ambiguidades globais e locais, definindo qual a regra da gramática a ser aplicada (ou seja, um mecanismo para decidir qual análise - ou análises - escolher num certo ponto da sentença).

9 Ainda como a sentença anterior, esta também não é um exemplo preciso de labirinto sentencial, porque ela não apresenta ambigüidade estrutural temporária - sua ambiguiidade é global e só pode ser resolvida no contexto. Num contexto neutro, porém, no qual não saibamos que filmes foram vistos pela pessoa que pronuncia a sentença, provavelmente preferiremos a primeira interpretação; esta preferência é prevista pelo princípio de associação à direita. Efetivamente, a piada mencionada na nota 7 se baseava nesta expectativa, ainda que o seu contexto fosse mais específico. 
Essa hipótese, atribuída a Joan Bresnan (1982; e, mais especificamente, Bresnan; Kaplan, 1982), que postula um homomorfismo entre a gramática e o analisador gramatical, é conhecida como hipótese forte da competência. De acordo com esta hipótese, não basta apenas que as cadeias linguiísticas sejam semelhantes às previstas pela gramática da língua (equivalência fraca), nem que elas apresentem as mesmas estruturas determinadas por esta gramática (equivalência forte), se os seus princípios não forem empregados explicitamente; nesse caso, teríamos apenas o que, nos termos de Bresnan, corresponderia à hipótese fraca da competência.

Uma aplicação radical desta hipótese nos levaria à conclusão de que são os próprios princípios da gramática que conduzem a análise gramatical; numa aplicação mais moderada, precisaríamos nos perguntar como o "mecanismo para a construção de estruturas interpretáveis" considera os princípios gramaticais. Um exemplo de aplicação moderada da hipótese forte da competência é o analisador por deslocamento-e-redução, de Pereira (1985), no qual os princípios gramaticais ficam completamente subordinados ao analisador gramatical. ${ }^{10}$

Para Steedman (1989, p. 464), por exemplo, "quando considerado em conjunto com a nossa incontestável intuição de que a compreensão é incremental, isto nos conduz imediatamente a um paradoxo. Quase nada do que sabemos sobre a gramática das línguas naturais parece ocorrer como seria de esperar se esta hipótese fosse mantida".

Mas, segundo o próprio Steedman (1989, p. 465-466),

Existem várias maneiras de escapar deste aparente paradoxo. Talvez a mais fácil seria a de assumir que a Hipótese Forte da Competência esteja simplesmente errada, e que as etapas do processamento não sejam de fato relacionadas à gramática regra-a-regra. Essa estratégia tem sido regularmente adotada pelos linguiistas, porque ela thes garante ao menos um programa de pesquisa coerente. A hipótese da competência não seria mais do que um instrumento heurístico, já que as questões relativas à realidade psicológica da interpretação incremental e à natureza da

10 Há uma implementação em Prolog do analisador por deslocamento-e-reduçāo em Covington (1994, p. 159). 
gramática são logicamente independentes. A demonstração dessas questões não é suficiente para falsificar a gramática gerativa ortodoxa; não há nenhuma necessidade para esta relação. [...] No entanto, em relação às línguas humanas, há um custo em termos da parcimônia da teoria, pois desistir da Hipótese Forte da Competência é desistir da plasticidade no seu desenvolvimento. [...] Uma segunda maneira de escapar do paradoxo é negar a nossa intuição de que a interpretação incremental exista. Esta estratégia é comum entre os psicólogos experimentais, que têm relutado em abandonar os apelos da Hipótese Forte da Competência, como era de se esperar. A alegação é a de que a impressão de incrementalidade da interpretação é uma ilusão induzida pela natureza previsível e pela extrema rapidez do próprio processamento sintático, pelo modo como o contexto torna a própria mensagem redundante, ou então por processos de interpretação semântica completamente autônomos, independentes da análise sintática. [...]

O que poucas vezes se percebe é que há uma terceira forma, potencialmente mais vantajosa, de se escapar do paradoxo: mantendo a Hipótese Forte da Competência e continuando a respeitar nossas intuições sobre a semântica incremental, mas rejeitando as teorias de gramática estabelecidas.

Além da gramática lexical-funcional, da própria Bresnan, o outro paradigma gramatical apontado como sendo capaz de se adequar à hipótese forte da competência e à incrementalidade da interpretação é o da gramática categorial, " na qual "o efeito da regra de Composição Funcional é o de converter as estruturas ramificadas à direita, que resultariam da mera aplicação funcional das categorias no exemplo acima, em estruturas ramificadas à esquerda" (Steedman, 1989, p.

11 Omitiremos aqui qualquer apresentação dos prinćpios da gramática categorial e de seu funcionamento, já que eles constam da apresentação desta série de artigos.

12 No diagrama proposto por Steedman, os dois últimos constituintes apresentam ramificaçāo direita, apesar do que ele havia dito. Este detalhe deve ter escapado ao autor, já que o mesmo esquema que permite a mudança para a ramificação à esquerda em todo o resto da árvore também se aplicaria a esta parte. Admitindo que cakes seja do tipo N, those seria do tipo NP/N, e restaria a seguinte cadeia categorial a ser exponenciada: S/NP NP/N N. Aplicando-se a composição funcional às duas primeiras, obteríamos: S/N N; e finalmente, por aplicação funcional, S. Assim também chegariamos ao mesmo expoente, só que apenas com ramificações à esquerda. 


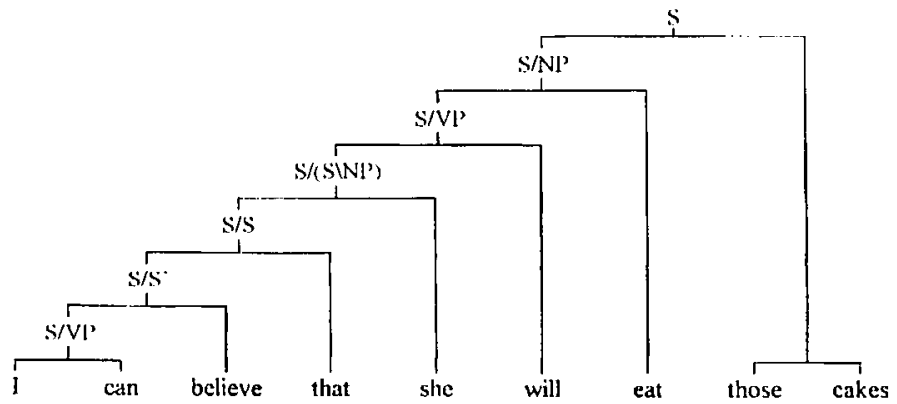

481). O "exemplo acima", mencionado na citação, é a análise da sentença I can believe that she will eat those cakes que, recorrendo-se à gramática categorial, fica da seguinte maneira: ${ }^{12}$

Ao contrário de uma análise gerativista, que resultaria necessariamente numa árvore com ramificações para ambos os lados, a análise categorial permite uma estrutura ramificada apenas à esquerda. Só que esse tipo de ramificação não seria o único permitido pela gramática categorial para a mesma seqüência categorial; caso dispuséssemos apenas da aplicação funcional, como na época em que Ajdukiewicz (1935) propôs as bases desta gramática, a única análise possível precisaria de ambas as ramificações - a menos que abandonássemos completamente as categorias aristotélicas. Na verdade, não se pode nem mesmo dizer que a análise com ramificação apenas à esquerda seja a mais simples, já que é preciso recorrer à composição funcional - uma extensão do cálculo categorial - e, além disso, em alguns casos, até mesmo ao alçamento de tipo (type raising), como no caso da quantificação generalizada, que obriga o que antes seriam apenas duas operações de aplicação funcional a uma sequiência de três operações: alçamento de tipo, composição funcional e aplicação funcional.

13 No texto já mencionado na nota 1 (Stabler, 1992), o que ele demonstra efetivamente é que uma determinada implementação em DCG (definite clause grammar) de uma gramática independente de contexto (context-free grammar), apesar de sua estratégia descendente (top-down), é capaz de executar a análise da cadeia lingüística incrementalmente, explorando completamente todos os níveis informacionais das menores unidades lingüísticas; o que não garante, de forma alguma, que a gramática gerativa em si possua a mesma propriedade. No entanto, o mesmo autor implementou em 


\section{Conclusão}

Apesar de Stabler ter mostrado que uma gramática gerativa não é incompatível nem com uma interpretação incremental, nem com a hipótese forte da competência $^{13}$ - acarretando, portanto, o enfraquecimento da acusação de Steedman -, isso não altera a constatação de que a gramática categorial demonstra ser mais transparente aos dois princípios citados, e principalmente à incrementalidade. No entanto, isso não é bastante para garantir que a solução de Steedman seja a mais adequada do ponto de vista psicolingüístico. Em pelo menos dois pontos, a proposta de Steedman parece falhar: 1) ela não é muito clara em relação a uma questão computacional - a de como garantir a primazia da ramificação à esquerda com a análise categorial - e 2) ela despreza completamente uma questão epistemológica - a da necessidade da explicitação formal de uma teoria do desempenho.

Prolog o modelo de regência e ligação (Stabler, 1992a); mas devido principalmente ao tamanho da formalização, e também à complexidade formal à qual o autor recorreu para apresentar esta sua implementação, ainda não nos foi possível avaliar se ela comprova a incrementalidade da gramática gerativa, pelo menos em seu modelo de regência e ligação - tampouco parecia ser este um objetivo do autor. No seu livro, Crocker (1996, p.19l e ss.) também apresenta uma implementação em Prolog do modelo de regência e ligação, onde defende explicitamente a incrementalidade da gramática gerativa; porém a incrementalidade é garantida por uma técnica computacional - o congelamento (freezing), cujas consequiências para um modelo psicolingǘstico ainda não pudemos avaliar-e não por princípios determinados pela própria gramática.

14 Uma das principais características da gramática categorial - alguns diriam: o seu maior defeito - é a multiplicação infinita da possibilidade de análises, muitas delas não levando sequer a uma diferença estrutural - o que é conhecido como ambigüidade espúria. Essa questão nos parece equivocada na medida em que cobra determinismo de uma teoria lógica para a qual essa questão não é relevante. Principalmente dentro de um modelo modularista que prevê uma parte näo-determinística (competência) e outra determinística (desempenho), como a que estamos considerando, a questão se toma completamente irrelevante, já que ao módulo gramatical cabe apenas licitar ou determinar a validade das análises, enquanto a seleção de qual análise executar -e principalmente qual considerar primeiro - cabe ao módulo psicolingüístico.

15 Devido à ambiguiidade espúria, comentada anteriormente, não há limites para a quantidade de análises possíveis mesmo para esta seqüência de dois tipos, já que sempre é possível aplicar o alçamento de tipo em qualquer uma das duas categorias de forma a obter um novo tipo que permita a aplicação funcional; a composição funcional não entra aqui porque ela exige mais de dois tipos para poder ser aplicada.

16 Preferimos adotar aqui uma notação mais difundida para a análise gramatical como dedução (parsing as deduction). 
Em relação à questão computacional, Steedman nem chega a afirmar que uma análise categorial permite a construção de outras estruturas que não apenas a de ramificação à esquerda. ${ }^{14}$ Para uma seqüência de dois tipos, como $n \mathrm{~s}$ n, por exemplo, há pelo menos duas análises possíveis: ${ }^{15} 1$ ) por uma única aplicação funcional à esquerda $(\mathrm{af}<),{ }^{16} \mathrm{e} 2$ ) primeiro por um alçamento de tipo (at) de $n$, seguido por uma aplicação funcional à direita $(\mathrm{af}>)$.

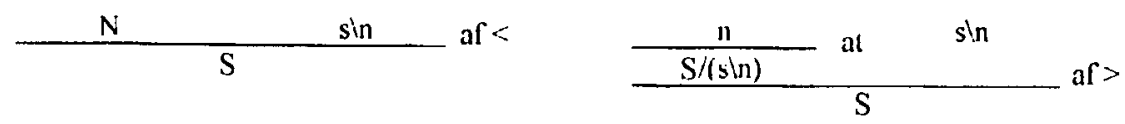

Este exemplo explicita se não um paradoxo, pelo menos uma contradição computacional da proposta de Steedman: a primeira análise parece mais econômica do que a segunda, na medida em que emprega menos operações; no entanto, por apresentar ramificação apenas à esquerda, e ser portanto mais compatível com a interpretação incremental, a segunda parece resultar numa estrutura cuja interpretação é mais fácil do que a da primeira. Assim, para essa proposta de Steedman poder funcionar efetivamente, ainda é preciso especificar explicitamente os critérios que priorizam um produto mais simples (sem ramificações para ambos os lados), apesar de resultar de um processo mais complexo (com aplicação de mais operações). Mas isso não foi feito por Steedman.

Essa mesma exigência de formalização nos leva à questão da condição de uma teoria do desempenho no processamento lingüístico. A questão aqui é se as estratégias de solução local, impostas por uma interpretação incremental, são apenas uma heurística que o modelo precisa respeitar (o que, por analogia aos termos de Bresnan, chamaremos de hipótese fraca do desempenho), ou se ela precisa ser explicitamente formulada no modelo (o que chamaremos, então, de hipótese forte do desempenho).

O modelo proposto por Steedman, bem como os outros citados aqui (o de Stabler, o de Pereira, e mesmo o de Crocker, que se dispõe a ser uma teoria do desempenho), se adequam à hipótese fraca do desempenho, já que as restrições psicolingüísticas não são expressas direta e explicitamente - o modelo é construído de forma a apresentar apenas o funcionamento previsto pela teoria. Nesses modelos, os princípios de ligação mínima e de associação à direita não estão formalmente descritos, mas a análise de qualquer cadeia linguiistica resulta numa estrutura que não viola os princípios psicolingüísticos - ou pelo menos sempre é possível encontrar essa estrutura.

Para exemplificar, apresentaremos abaixo dois fragmentos, implementados

17 As reticências não fazem parte da linguagem Prolog - elas são apenas um recurso para indicar que uma definição ainda precisa ser completada; por isso, apenas o primeiro fragmento funciona efetivamente. Mas como sua função era apenas a de ilustrar a inclusão de um módulo responsável pelo desempenho, e não a de ser efetivamente um processador, só incluímos as aplicações funcionais à esquerda e à direita. 
em Prolog, ${ }^{17}$ das hipóteses forte e fraca do desempenho; e, apesar de ambos respeitarem a hipótese forte da competência, apenas o segundo respeita a hipótese forte do desempenho. No primeiro fragmento, a análise gramatical é conduzida pelo predicado combina, que define as regras de aplicação funcional (duas primeiras proposições); as capacidades psicolingüísticas da ligação mínima e da associação à direita estão indiretamente embutidas no modo como a recursividade é estabelecida (duas últimas proposições) - o algoritmo sempre tenta inicialmente associar os dois primeiros termos, e só depois de falhar é que permite procurar outras associações.

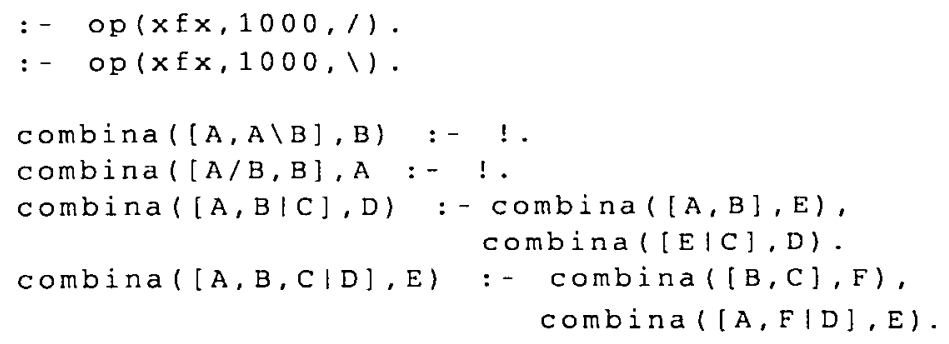

No segundo fragmento, ainda que o processamento seja inicialmente conduzido pela gramática, seus resultados são imediatamente submetidos aos princípios de desempenho; neste algoritmo, o módulo psicolingüístico é explicitamente definido através do predicado desempenho, que se caracteriza pelos princípios de ligação mínima e de associação à direita - predicados ' 1 igação mínima'e 'associação à direita'.

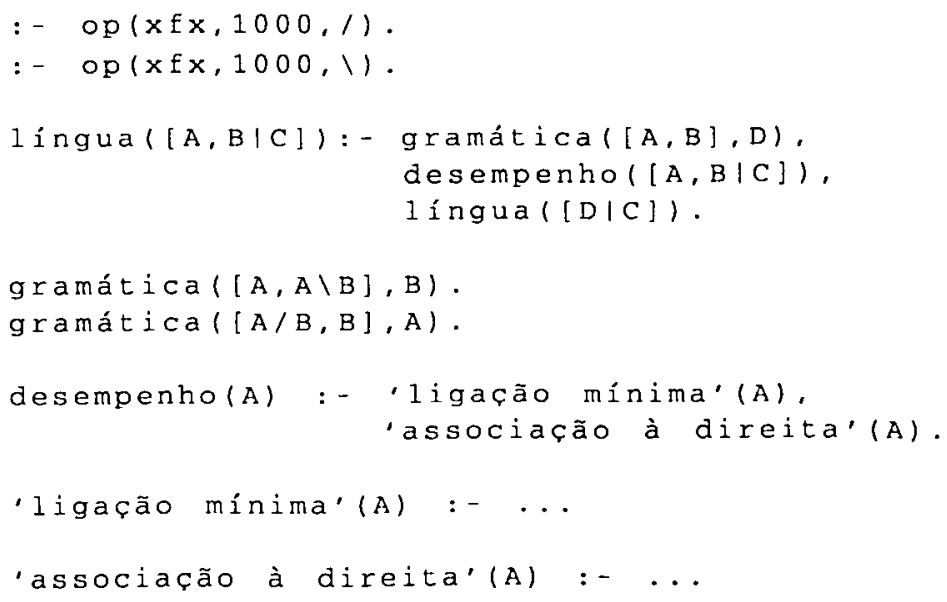


Para concluir, como pudemos observar, um modelo para uma teoria do processamento lingüístico humano não pode considerar apenas uma gramática enquanto "definição abstrata de um conjunto de objetos cuja estrutura é bemformada" (Gazdar; Mellish, 1985, p. 5). Um modelo deste tipo precisa ainda incluir um analisador gramatical que determine qual, dentre as estruturas permitidas pela gramática, é a mais adequada para um determinado ponto do processamento. Do ponto de vista computacional, uma implementação que não apresente explicitamente uma teoria do desempenho, mas apenas a respeite, pode até ser mais simples e funcionar como modelo do processamento lingüístico; no entanto, do ponto de vista psicolingüístico, esse modelo não tem nenhuma relevância teórica - a menos que não se acredite na realidade psicológica das teorias psicolingüísticas.

\title{
RESUMO
}

A partir do conceito de "interpretação incremental" e da proposta de Steedman para a solução dos problemas da contradição direcional entre a ramificação à direita e a ramificação à esquerda, faz-se uma discussão sobre a relação entre a proposta de Steedman e os princípios psicolingüísticos de "ligação mínima" e de "associação à direita", concluindo-se que qualquer proposta de gramática, que pretenda ser psicologicamente real, para ser teoricamente relevante, necessita levar em consideração uma teoria do desempenho.

Palavras-chave: gramática categorial, linguagem e cognição, ciência cognitiva.

\begin{abstract}
From the concept of "incremental interpretation" and Steedman's proposal of problem solution concerning the directional contradiction between the right and the left wings, a discussion about Steedman's ideas and the psycholinguistic principles of "minimum connection" and "joining the right wing" takes place. It is concluded that any grammatical proposal, which at least tries to be psychologically associated, needs to take into account a performance theory.
\end{abstract}

Key-words: categorial grammar, language and cognition, cognitive science. 


\section{REFERÊNCIAS BIBLIOGRÁFICAS}

BEVER, Thomas. The cognitive basis for linguistic structure. In: HAYES, J. R. (Ed.). Cognitive development of language. New York: Wiley, 1970.

BRESNAN, Joan. (Ed.). The mental representation of grammatical relations. Cambridge, Massachusetts: The MIT Press, 1982.

; KAPLAN, Ronald M. Introduction: Grammars as mental representations of language. In: BRESNAN, J. (Ed.) 1982. p. xvii-lii, 1982.

COVINGTON, Michael A. Natural language processing for prolog programmers. Englewood Cliffs, New Jersey, 1994.

CROCKER, Matthew W. Computational psycholinguistics - an interdisciplinary approach to the study of language. Dordrecht: Kluwer, 1996.

FRAZIER, Lyn. On comprehending sentences: syntactic parsing strategies. Bloomington, Indiana, 1979. $\mathrm{PhD}$ thesis - Indiana University Linguistics Club.

; CLIFTTON JR., Charles. Construal. Cambridge, Massachusetts: A Bradford Book, The MIT Press, 1996.

; RAYNER, K. Making and correcting errors during sentence comprehension: eye movements in the analysis of structurally ambiguous sentences. Cognitive Psychology, v. 14, p. 178-210, 1982.

GAZDAR, Gerald; MELLISH, Christopher S. Natural language processing in prolog - an introduction to computational linguistics. Wokingham: Addison-Wesley, 1989.

PEREIRA, Fernando C. N. A new characterization of attachment preferences. In: DOWTY, David R.; KARTTUNEN, Lauri; ZWICKY, Arnold M. (Eds.). Natural language parsing - psychological, computational, and theoretical perspectives. Cambridge: Cambridge University Press, 1985. p. 307-319.

STABLER JR., Edward P. Avoid the pedestrian paradox. In: BERWICK, Robert C.; ABNEY, Steven P.; TENNY, Carol (Eds.). Principle-based parsing: computation and psycholinguistics, Dordrecht: Kluwer, 1992.

. The logical approach to syntax - foundations, specifications, and implementations of theories of government and binding. Cambridge, Massachusetts: A Bradford Book, The MIT Press, 1992.

STEEDMAN, Mark J. Grammar, interpretation, and processing from the lexicon. In: MARSLEN-WILSON, William (Ed.). Lexical representation and process. Cambridge, Massachusetts: A Bradford Book, The MIT Press, 1989. p. 463-504. 